\title{
Let-7: A regulator of the ER $\alpha$ signaling pathway in human breast tumors and breast cancer stem cells
}

\author{
XIN SUN, SIDA QIN, CHONG FAN, CHONGWEN XU, NING DU and HONG REN \\ Department of Oncology, The First Affiliated Hospital of Xi'an Jiaotong University \\ School of Medicine, Xi'an, Shaanxi 710061, P.R. China
}

Received December 7, 2012; Accepted February 11, 2013

DOI: 10.3892/or.2013.2330

\begin{abstract}
The oncogenic role of estrogen receptor (ER) $\alpha$ and its correlation with let-7 microRNAs (miRNAs) have been studied and confirmed in breast tumors; however, this correlation has not been investigated in breast cancer stem cells (BCSCs). In the present study, we detected the expression of let-7 and ER $\alpha$ in ER-positive breast tumor tissues. Furthermore, we used a FACSAria cell sorter to separate side population (SP) cells from the MCF-7 and T47-D cell lines by Hoechst 33342 staining. The expression of let-7 miRNAs, ER $\alpha$ and its downstream genes in SP and non-SP (NSP) cells were analyzed. In additional experiments, we transfected a plasmid expressing let-7a into SP cells isolated from the MCF-7 and T47-D cell lines in order to observe changes in the expression of downstream genes (cyclin D1 and pS2). The correlation among let-7, $\mathrm{ER} \alpha$ and $\mathrm{ER} \alpha$ downstream genes suggested that let- 7 acts as a tumor suppressor by inhibiting ER $\alpha$-mediated cellular malignant growth in ER-positive breast cancer stem cells. The suppression of ER $\alpha$ by the upregulation of let-7 expression may be a promising strategy for the inhibition of the ER signaling pathway and for the elimination of cancer stem cells, thus aiding in the treatment of breast cancer.
\end{abstract}

\section{Introduction}

MicroRNAs (miRNAs or miRs), one of the most abundant classes of post-transcriptional regulators, are attracting increasing attention. MiRNAs inhibit translation initiation by binding to 3' untranslated regions (3'UTRs) (1). The upregulation of certain miRNAs in carcinoma suggests that they can function as oncogenes, and inversely, the downregulation of certain miRNAs suggests that they can also function as tumor

Correspondence to: Professor Hong Ren, Department of Oncology, The First Affiliated Hospital of Xi'an Jiaotong University School of Medicine, 277 Yanta West Road, Xi'an, Shaanxi 710061, P.R. China E-mail: renhongs2000@yahoo.com.cn

Key words: breast tumor, breast cancer stem cell, let-7 microRNAs, estrogen receptor $\alpha$ signaling, targeted therapy suppressors (2-4). Let-7 miRNAs are the earliest discovered miRNAs, which are critical for cell generation and differentiation (5). Let-7 miRNAs have been reported to be tumor suppressors, playing critical roles in tumorigenesis and the metastatic progression of many types of cancer, such as breast, lung, colorectal and ovarian cancer, as well as nervous system neoplasms $(6,7)$. Let-7 miRNAs have been demonstrated to regulate multiple oncogenes, such as RAS, high-mobility group AT-hook 2 (HMGA2), c-Myc and caspase-3, by targeting and degrading their mRNAs $(6,8,9)$. Let-7a, a member of the let-7 family, has been selected as a representative by a number of studies (10-13).

Estrogen has been implicated in breast diseases for a number of years, particularly in estrogen receptor (ER)-positive breast cancer. ER consists of two isoforms, ER $\alpha$ and ER $\beta$. The biological function of estrogen is mediated mainly by nucleus-localized ER $\alpha$, which is a critical component in breast cancer initiation and progression. Along with the discovery of anti-estrogen drugs and estrogen receptor antagonists, such as tamoxifen and letrozole, endocrine therapy plays a vital role in combating breast cancer. However, patients inevitably develop resistance to these drugs. Finding a novel strategy to inhibit the function of estrogen is crucial. Cancer stem cells (CSCs) are a group of cells showing a high capacity for sphere formation, self renewal, tumorigenicity and migration (14). Based on these characteristics, CSCs are considered responsible for resistance to chemo- and radiotherapy $(14,15)$, eventually promoting the regeneration and recurrence of cancer. Therefore, therapies targeting CSCs may be promising strategies for the treatment of breast cancer. However, it is remarkable that CSCs can remain dormant (in 'hibernation') for long periods of time, a quiescence associated with slow cell cycle kinetics, which renders CSCs resistant to anticancer therapies and enhances their tumor initiating potential $(16,17)$.

Recently, scientists discovered that let-7 degrades ER $\alpha$ as a target, and then inhibits cell proliferation and promotes cell apoptosis (18). This discovery suggests that let-7 miRNAs may be candidates for drug therapies against estrogen and cancer in the future. However, the function of let-7 related to ER $\alpha$ in breast cancer stem cells (BCSCs) has not yet been investigated. The isolation of CSCs has provided us with the opportunities to explore their origin, self-renewal, differentiation, invasiveness, metastatic ability, resistance to chemotherapy and radiotherapy $(19,20)$. The side population (SP) method was 
created as a classic and non-specific method for the separation of CSCs, which relies on their characteristics (21), and is particularly useful in a situation where molecular markers of these stem cells are unclear $(22,23)$. Previous studies have confirmed that SP cells are an enriched source of CSCs, and based on the lack of accumulation of the Hoechst dye, SP cells have been proven to enrich primitive and undifferentiated cells in a variety of tumors and cell lines (24). In this study, we applied the SP method to separate SP cells from breast cancer cell lines for research purposes.

In order to verify our hypothesis that let-7 is a regulator of the ER $\alpha$ signaling pathway in breast tumors and BCSCs, we firstly examined clinical specimens to search for clues of the correlation between let-7 and ER $\alpha$, and then detected their expression in BCSCs to identify the signaling pathway associated with let-7. Finally, we transfected let-7a into SP cells to investigate the changes in the expression of target genes and biological characteristics.

\section{Materials and methods}

Expression of let-7 and ER $\alpha$ in clinical specimens. To examine the expression of hsa-let-7 and ER $\alpha$, specimens from 43 patients with ER-positive breast cancer were collected. These patients underwent surgery at the First Affiliated Hospital of Xi'an Jiaotong University (Xi'an, China) from February 2009 to February 2011. Standard modified radical mastectomy was performed for each patient, with or without sentinel lymph node dissection and complete axillary lymph node dissection. No pre-operative chemo- or radiotherapy was performed on any of these patients. Tumor tissue specimens were from the central part of the tumor, except for the necrotic part; normal tissue specimens were obtained from tissue located $>5 \mathrm{~cm}$ away from the tumor margin. Fresh specimens were stored in liquid nitrogen. All the patients were diagnosed and confirmed by pathological examination. Their clinical data are summarized in Table I.

The expression levels of let- 7 and ER $\alpha$ were examined by real-time quantitative reverse transcription-polymerase chain reaction (qRT-PCR). The cDNA templates for qRT-PCR were synthesized from extracted RNA samples. The primers of the let-7 miRNAs are listed in Table II. Primers of ER $\alpha$ were: 5'-ATG ACC ATG ACC CTC CAC ACC AAA GCA-3' and 5'-TTC AGA CCG TGG CAG GGA AAC CCT CT-3'. miR-U6 and $\beta$-actin were used as the internal reference. Gene expression was detected using SYBR Premix Ex TaqII (Takara, Inc., Dalian, China). Real-time PCR was carried out in a $20.0 \mu 1$ reaction volume, including $10.0 \mu 1$ of SYBR Premix Ex TaqII, $0.8 \mu \mathrm{l}$ certain let-7 miRNA primer and $0.8 \mu \mathrm{l}$ Uni-miR qPCR Primer (Takara, Inc.). ER $\alpha$ was determined by adding $1.0 \mu \mathrm{l}$ forward primer and $1.0 \mu \mathrm{l}$ reverse primer of ER $\alpha$ (AuGCT DNA; Syn Biotechnology, Xi'an, China). All analyses were performed in triplicate.

Cell culture. The human breast cancer cell lines, MCF-7 and T47-D, were kept in the Central Laboratory of the Medical College of Xi'an Jiaotong University. RPMI-1640 medium (Thermo Scientific Co., Ltd., Shanghai, China) was supplemented with $10 \%$ fetal bovine serum, penicillin $100 \mathrm{U} / \mathrm{ml}$ and streptomycin $100 \mathrm{mg} / \mathrm{ml}$ (Gibco-Invitrogen, Grand Island,
Table I. Clinical and pathological features of the breast cancer patients.

\begin{tabular}{lcc}
\hline Parameter & No. of cases & Percentage \\
\hline Age (years) & & \\
$\leq 50$ & 19 & 44.2 \\
$>50$ & 24 & 55.8 \\
Menopause & & \\
Pre & 20 & 45.1 \\
Post & 23 & 55.9 \\
Tumor size (cm) & & \\
$\leq 2$ & 27 & 62.8 \\
$>2$ & 16 & 37.2 \\
Grade of malignancy & & \\
G1 + G2 & 31 & 72.1 \\
G3 & 12 & 27.9 \\
Progesterone status & & \\
Positive & 33 & 76.7 \\
Negative & 10 & 23.3 \\
HER2 status & & \\
Overexpression & 35.6 & \\
Normal expression & 35 & \\
Ki-67 & & \\
$\leq 25 \%$ & & \\
$>25 \%$ & & \\
\hline
\end{tabular}

HER2, human epidermal growth factor receptor 2.

$\mathrm{NY}$, USA). MCF-7 and T47-D were incubated at $37^{\circ} \mathrm{C}$ in a $5 \%$ $\mathrm{CO}_{2}$ atmosphere. SP cells separated from MCF-7 and T47-D cells were cultured in stem cell growth medium (SCGM), which was DMEM/F12 (Thermo Scientific Co., Ltd.) medium supplemented with $1 \%$ non-essential amino acid, $5 \mathrm{mM}$ HEPES, $50 \mu \mathrm{g} / \mathrm{ml}$ insulin, $20 \mathrm{ng} / \mathrm{ml}$ human epidermal growth factor (hEGF), $10 \mathrm{ng} / \mathrm{ml}$ human basic fibroblast growth factor (hbFGF) $(3,19,25,26)$.

Isolation of breast CSCs (SP cells). In this study, we used a FACSAria cell soter (BD Biosciences, San Jose, CA, USA) in order to separate SP cells from MCF-7 and T47-D cell lines. The SP protocol was essentially performed as previously described (21). DNA-specific Hoechst 33342 dye and verapamil hydrochloride were purchased from Sigma-Aldrich Co., Ltd. (St. Louis, MO, USA) MCF-7 and T47-D cells were collected $\left(1 \times 10^{6}\right.$ cells $\left./ \mathrm{ml}\right)$, and incubated in RPMI-1640 medium as described above. The positive group contained $5 \mu \mathrm{g} / \mathrm{ml}$ Hoechst 33342 , and was incubated at $37^{\circ} \mathrm{C}$ for $90 \mathrm{~min}$ in SCGM. The control group contained the ABCG inhibitor, verapamil $(1 \mathrm{mM})$, with the other conditions being the same. Four groups of two breast cancer cell lines were analyzed by flow cytometry. After the SP and non-SP (NSP) cells were successfully separated, we re-analyzed the cells to evaluate sorting purity. We separated the SP cells in three rounds. 
Table II. Let-7 miRNAs and U6 primers.

\begin{tabular}{llc}
\hline \multicolumn{1}{c}{ Primer } & $\begin{array}{c}\text { Annealing } \\
\text { temp }\left({ }^{\circ} \mathrm{C}\right)\end{array}$ \\
\hline miR-let-7a & TGAGGTAGTAGGTTGTATAGTT & 54.7 \\
miR-let-7b & TGAGGTAGTAGGTTGTGGTT & 58.3 \\
miR-let-7c & TGAGGTAGTAGGTTGTATGGTT & 56.3 \\
miR-let-7d & TCTCCATCATCCAACGTATCAA & 57.1 \\
miR-let-7e & ACTCCATCCTCCAACATATCAA & 57.3 \\
miR-let-7f & GATATGTTAGATAACGGAAGGG & 56.8 \\
miR-let-7g & ACTCCATCACCAAACATGTCAA & 59.0 \\
miR-let-7i & GACGCGTTCGATGACGGAACGA & 58.5 \\
U6-F & CTCGCTTCGGCAGCACA & 56.0 \\
\hline
\end{tabular}

temp, temperature.

Total RNA and protein were extracted and identified and the average expressions were calculated.

Analysis of let-7 and ER $\alpha$. Total RNA was extracted using Takara RNAiso Plus (Takara, Inc.), then cDNA was synthesized using $1.0 \mu \mathrm{l}(\sim 1.0 \mu \mathrm{g})$ total RNA in a reaction volume of $20.0 \mu 1$ by following the protocol of Takara One Step PrimeScript miRNA cDNA Synthesis Kit (Takara, Inc.). Following dilution for five times, $2.0 \mu \mathrm{l}$ cDNA was absorbed from $100.0 \mu \mathrm{lmix}$ for real-time PCR in a $20.0 \mu 1$ reaction volume, including $10.0 \mu \mathrm{l}$ of SYBR Premix Ex TaqII, $0.8 \mu \mathrm{l}$ certain let-7 miRNA primer and $0.8 \mu \mathrm{l}$ Uni-miR qPCR Primer (Takara, Inc.). The primers of let-7 family members used in this reaction are listed in Table II. The level of each miRNA was calculated and presented following the $2^{-\Delta \Delta \mathrm{Ct}}$ method $[\Delta \Delta \mathrm{Ct}=\Delta \mathrm{Ct}$ (SP cells) - $\Delta \mathrm{Ct}$ (NSP cells)], using miR-U6 as the internal reference for BCSCs.

To examine ER $\alpha$ expression in SP and NSP cells, total RNA was extracted, and the protocols were the same as those described above. When the mixture was ready for real-time PCR in a $20.0 \mu \mathrm{l}$ reaction volume, $1.0 \mu \mathrm{l}$ forward primer and $1.0 \mu \mathrm{l}$ reverse primer of ER $\alpha$ (AuGCT DNA; Syn Biotechnology) were added, not using Uni-miR qPCR Primer. The primers for ER $\alpha$ were: 5'-ATG ACC ATG ACC CTC CAC ACC AAA GCA-3' and 5'-TTC AGA CCG TGG CAG GGA AAC CCT CT-3'. The expression level of ER $\alpha$ was presented following the $2^{-\Delta \Delta \mathrm{Ct}}$ method, using $\beta$-actin as the internal reference, of which the primers were 5'-GGT GGC TTT TAG GAT GGC AAG-3' and 5'-ACT GGA ACG GTG AAG GTG ACA G-3'. All analyses were performed in triplicate.

Analysis of protein expression. Cyclin D1 and pS2 are the direct downstream genes of ER $\alpha$, and play an important role in the cell cycle, cell differentiation and proliferation. We investigated $\mathrm{ER} \alpha$, cyclin $\mathrm{D} 1$ and $\mathrm{pS} 2$ expression by western blot analysis in the SP cells. Firstly, total protein was extracted from the isolated SP and NSP cells by radioimmunoprecipitation assay (RIPA) lysis buffer. Following centrifugation, the supernatants were collected. Total protein concentrations were measured using the BCA assay kit. Clarified protein lysates were electrophoretically resolved on a denaturing SDS polyacrylamide gel (8-12\%) and electrotransferred onto nitrocellulose membranes.

The membranes were firstly blocked in 5\% non-fat dry milk in Tris-buffered saline (TBS) for $2 \mathrm{~h}$, and then probed with specific primary antibodies against ER $\alpha$ (ab10286), cyclin D1 (ab62151), pS2 (ab92377), purchased from Abcam (Hong Kong, China). Immunopositive bands were detected using the chemiluminescence detection system (Amersham Biosciences, Piscataway, NJ, USA) and autoradiography. The western blot analysis results were scored as positive if the band of interest was present at the expected molecular weight. All analyses were performed in triplicate.

Transfection of let-7a into SP cells. The let-7a sequence was synthesized and cloned into the carrier plasmid, pGenesil, by GenePharma Co., Ltd. (Shanghai, China), which contained neo gene; pGenesil-control was also constructed by GenePharma Co., Ltd. The resulting plasmids were labeled pGenesil-let-7a and pGenesil-control, confirmed by restriction enzyme digestion and agarose gel electrophoresis. In order to determine the effects of let-7a on ER $\alpha$, the pGenesil-let-7a plasmid was transfected into the SP cells from the MCF-7 and T47-D cell lines, using Lipofectamine 2000 according to the manufacturer's instructions. After $48 \mathrm{~h}$, the cells were placed in selection medium, and let-7a was detected. After the transfection of let-7a into MCF-7 and T47-D SP cells, we examined the mRNA and protein expression of ER $\alpha$. We also examined the protein expression levels of cyclin D1 and pS2 after transfection. The protocols were as described above.

Flow cytometry. MCF-7 and T47-D SP cells which were transfected with the let-7a and pGenesil-control plasmids were divided into the following four groups: i) MCF-7 let-7a positive group, ii) MCF-7 control group, iii) T47-D let-7a positive group and iv) T47-D control group.

For analysis of the apoptosis rates, $5 \times 10^{5}$ cells from each group were collected, and then washed with PBS twice. Flow cytometric analysis was carried out according to standard procedures. The cells were resuspended in $500 \mu \mathrm{l}$ binding buffer, and then $5 \mu 1$ Annexin V-FITC and $10 \mu \mathrm{l}$ PI (both from BD Biosciences) were added. The mixture was gently vortexed and then incubated for $15 \mathrm{~min}$ at $18-28^{\circ} \mathrm{C}$ in the dark. The cells were analyzed by flow cytometry within $1 \mathrm{~h}$ of incubation and all analyses were performed in triplicate.

For cell cycle analysis, $5 \times 10^{5}$ cells were collected, washed twice with PBS, and then fixed with ice-cold $70 \%$ ethanol for $24 \mathrm{~h}$ at $4^{\circ} \mathrm{C}$. The fixed cells were then stained with PI for $30 \mathrm{~min}$ at $37^{\circ} \mathrm{C}$; finally all samples were analyzed by flow cytometry. Cell cycle analysis of DNA contents was performed using MultiCycle software. All analyses were performed in triplicate.

Statistical analysis. All statistical analyses were performed using SPSS13.0 software (IBM Corp., Armonk, NY, USA). The results are presented as the means \pm standard deviation (SD). The intragroup differences of the miRNAs and protein expression were assessed by the analysis of variance (ANOVA) test. The statistical differences of let-7 and its downstream genes between the four groups were determined using the 
A

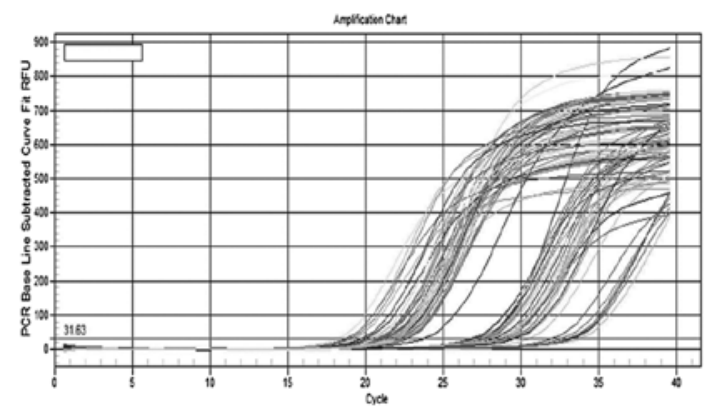

$\mathrm{C}$

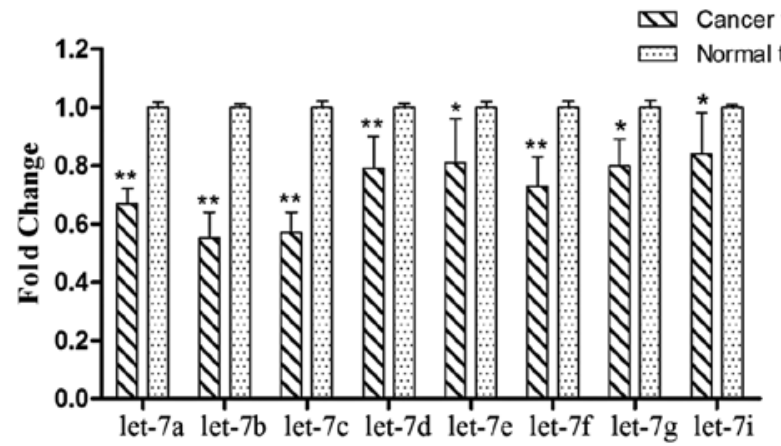

B

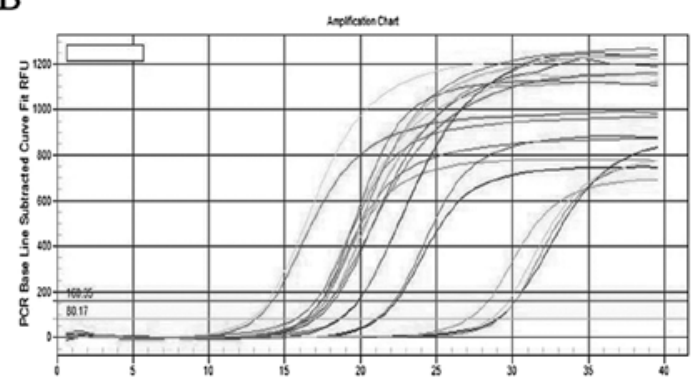

$\mathrm{D}$

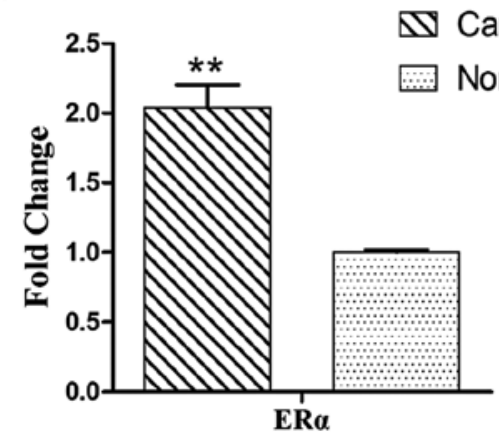

Figure 1. Expression of let-7 and estrogen receptor (ER) $\alpha$ in cancer and normal tissues. (A) Amplification curves of let-7 miRNAs in the samples of cancer and normal tissues. (B) Amplification curves of ER $\alpha$ in the samples of cancer and normal tissues. (C) Quantification of let-7 in cancer and normal tissues, the relative quantity was calculated by the $2^{-\Delta \Delta C t}$ method, using U6 as the internal reference. Statistical analysis was performed using the $\mathrm{t}-\mathrm{test}$, $\mathrm{P}<0.05$, ${ }^{* *} \mathrm{P}<0.01$. (D) Quantification of ER $\alpha$ in MCF-7 and T47-D side population (SP) cells, the relative quantity was calculated by $2^{-\Delta \Delta \mathrm{Ct}}$ method, using $\beta$-actin as the internal reference. Statistical analysis was performed using the t-test, ${ }^{* *} \mathrm{P}<0.01$.

Student's t-test. A P-value $<0.05$ was considered to indicate a statistically significant difference.

\section{Results}

Expression of let-7 and ER $\alpha$ in clinical specimens. The results of quantitative real-time PCR showed that let-7 miRNAs were downregulated in tumor tissues compared to normal tissues. Among all let-7 miRNAs, the differences of let-7a, let-7b and let-7c between the two groups were the most significant (Fig. 1A and C); on the contrary, ER $\alpha$ was significantly upregulated in the cancer tissues compared to the normal tissues (Fig. 1B and D). A significant inverse correlation was observed.

Isolation of SP cells. The SP cells from the MCF-7 and T47-D cells accounted for 5.0 and $3.3 \%$ of the total population, respectively. As expected, verapamil inhibited the proportion of SP cells. The proportion of MCF-7 and T47-D SP cells dropped to 0.4 and $0.1 \%$, respectively when verapamil was added into the process of separation in the control group. Representative data are shown in Fig. 2; these data are in general agreement with previous studies (26-30).

Expression of let-7 and its correlation with ER $\mathrm{mRNA}$. The results of quantitative real-time PCR showed that let-7 miRNAs were downregulated in the SP cells compared to the NSP cells; among them, let-7a/b/c were significantly downregulated (Fig. 3A and C); on the contrary, ER $\alpha$ was upregulated in the SP cells compared to the NSP cells (Fig. 3B and D). These two factors had a significant inverse correlation.
Expression of ER $\alpha$ downstream genes. We assessed the protein expression level of ER $\alpha$, cyclin D1 and pS2 in SP and NSP cells. The expression of ER $\alpha$, cyclin D1 and pS2 were significantly higher in the SP compared to the NSP cells; importantly, we detected an inverse correlation between cyclin D1, pS2 and let-7 (Fig. 4).

Let-7 targets ERa signaling pathway. PGenesil-let-7a and pGenesil-control plasmids were constructed; the recombinant vector was verified by sequencing and examined by qRT-PCR. Let-7a expression was significantly enhanced in the SP cells transfected with pGenesil-let-7a compared to the SP cells transfected with pGenesil-control after two days (Fig. 5). At the mRNA level, the results showed that let-7a inhibited ER $\alpha$ mRNA expression after two days (28-61\% of negative control, $\mathrm{P}<0.01$ ) (Fig. 6A), indicating that let-7a promotes the degradation of ER $\alpha$ mRNA. At the protein level, let-7a suppressed the expression of ER $\alpha$ (Fig. 6B). Furthermore, we examined the downstream genes of $\mathrm{ER} \alpha$ following transfection for two days; the results showed that let-7a significantly inhibited the expression of pS2 and cyclin D1 (Fig. 6B). The gray value results of western blot analysis are shown in Fig. 6C and D.

Cell cycle and apoptosis analysis of let-7a SP cells. Cell cycle analysis showed that let-7a increased the percentage of SP cells in the G0-G1 phase, and decreased the percentage of SP cells in the $\mathrm{S}$ phase, compared with the control group. The results of MCF-7 SP cells are shown in Fig. 7A and B, and the results of T47-D SP cells are shown in Fig. $7 C$ and $D, P<0.05$. These results indicate that let-7a promotes the G0-G1 transition, 
A
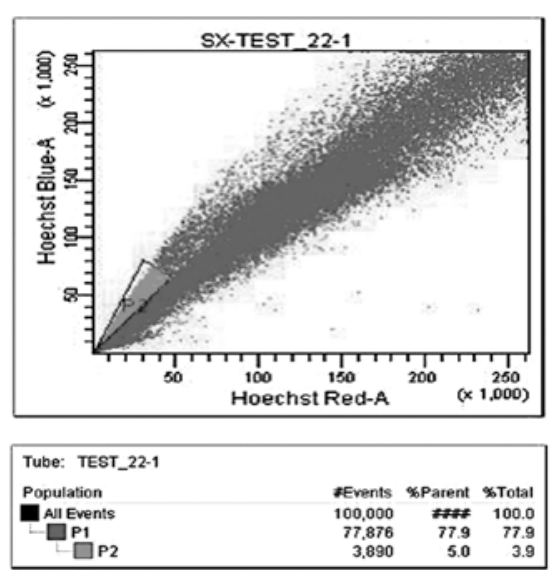

$\mathrm{C}$
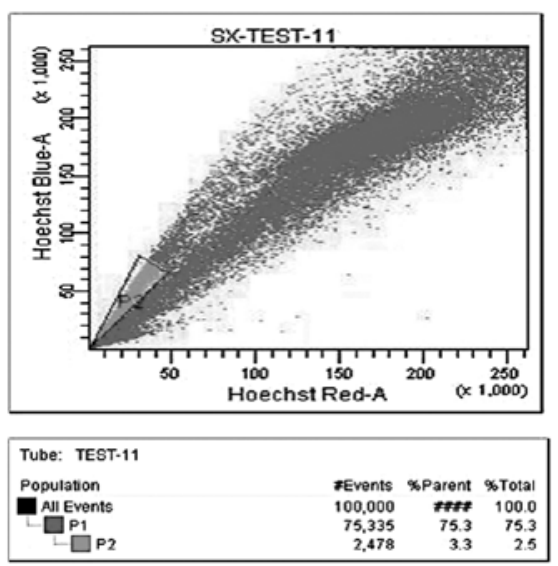

B
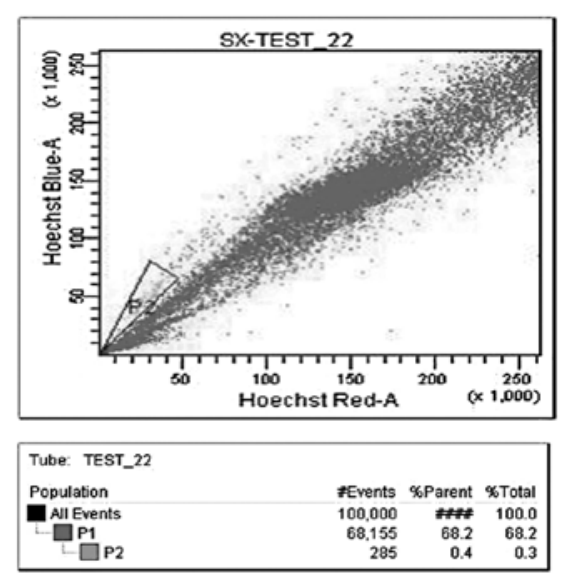

$\mathrm{D}$
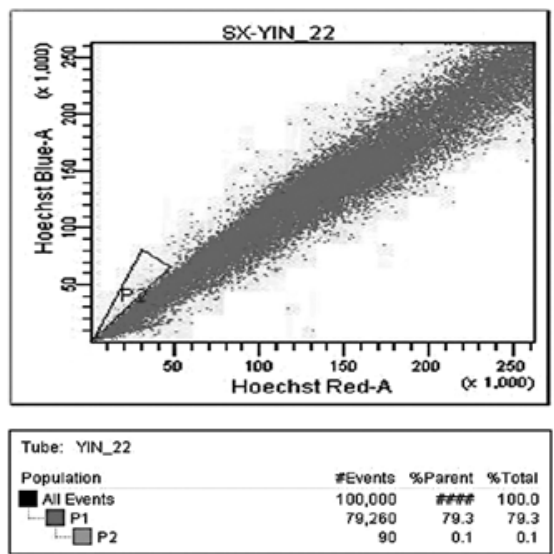

Figure 2. Hoechst 33342 staining patterns in MCF-7 and T47-D cells. The side population (SP) cells were analyzed in the MCF-7 cells (B) with or (A) without verapamil by Hoechst 33342 staining and flow cytometry. The same analysis was carried out for T47-D cells (D) with or (C) without verapamil. The area within the triangle represents SP cells, and the remaining area represents the non-SP (NSP) cells.

A

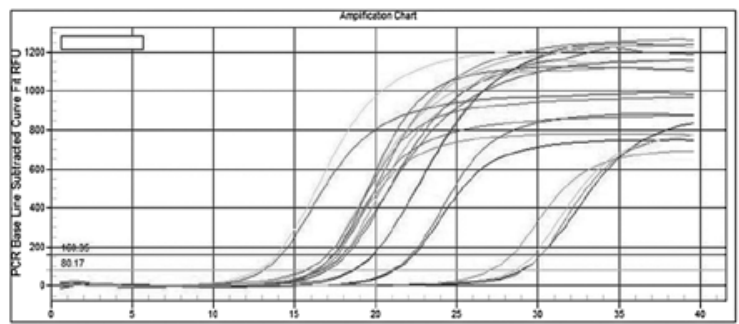

$\mathrm{C}$

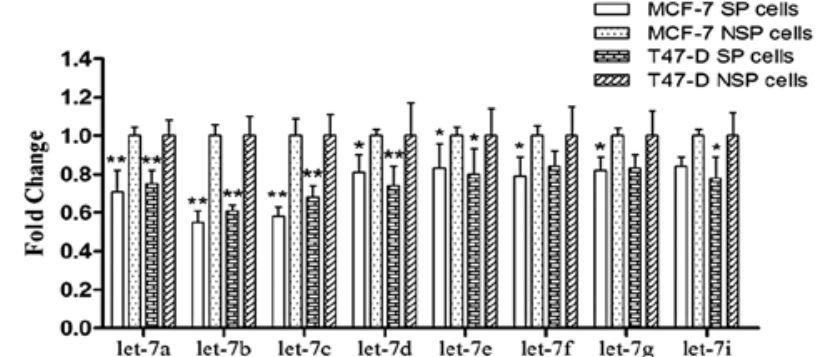

B

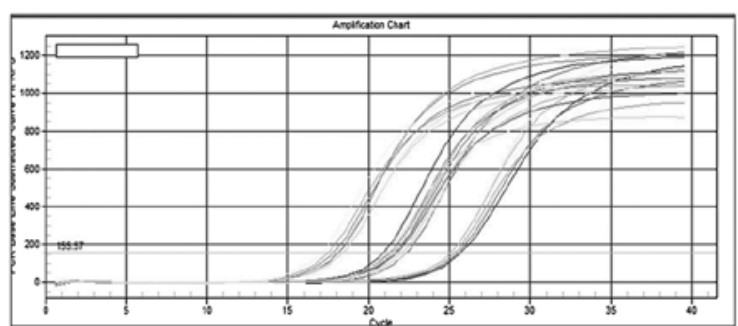

D

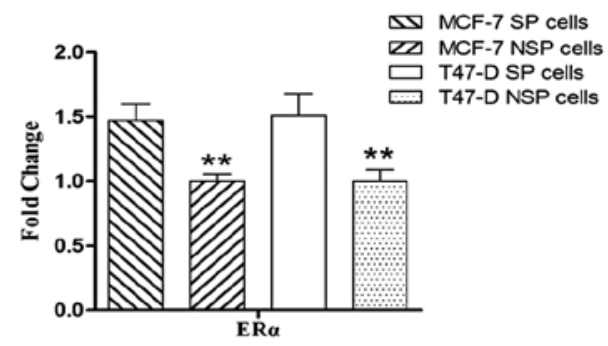

Figure 3. Expression of let-7 and estrogen receptor (ER) $\alpha$ in side population (SP) and non-SP (NSP) cells separated from the MCF-7 and T47-D cell lines. Amplification curves of (A) let-7 miRNAs and (B) ER $\alpha$ in MCF-7 and T47-D SP cells. Quantification of (C) let-7 family members and (D) ER $\alpha$ in MCF-7 and T47-D SP cells; the relative quantity was calculated by the $2^{-\Delta \Delta_{\mathrm{Ct}}}$ method using U6 as the internal reference. Statistical analysis was performed using the $\mathrm{t}$-test, ${ }^{*} \mathrm{P}<0.05,{ }^{* *} \mathrm{P}<0.01$.

and thereby inhibits SP cell proliferation. We then assessed SP cells from the two cell lines to examine the effect of let-7a on CSC apoptosis. The results showed that let-7a increased the apoptotic rate of MCF-7 and T47-D SP cells (Fig. 8). 
A

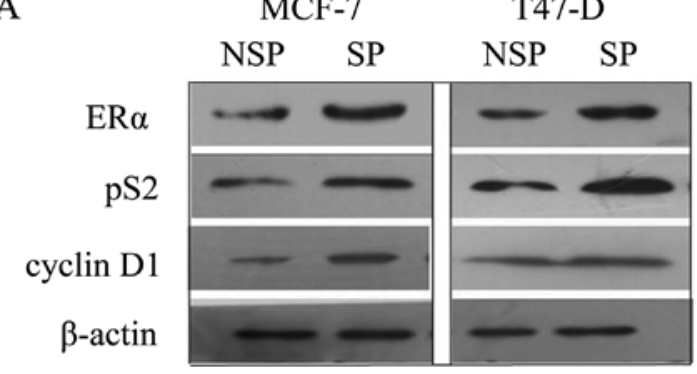

B

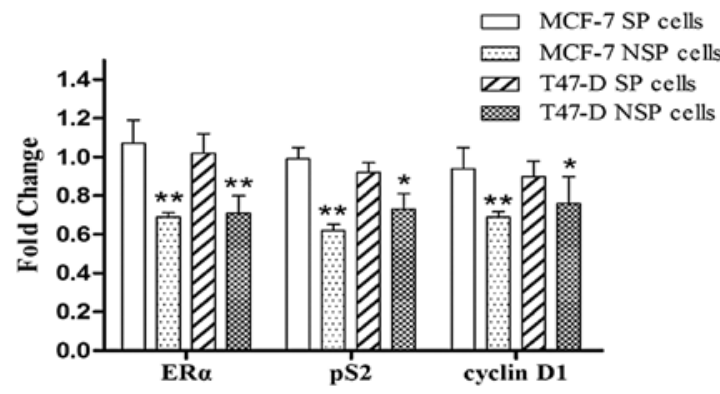

Figure 4. Western blot analysis of the direct downstream genes of estrogen receptor (ER) $\alpha$ signaling in side population (SP) and non-SP (NSP) cells separated from the MCF-7 and T47-D cell lines. (A) The protein levels of ER $\alpha, \mathrm{pS} 2$ and cyclin D1 were detected by western blot analysis in the MCF-7 and T47-D SP cells. (B) Gray value level of ER $\alpha$, cyclin D1, pS2 in MCF-7 and T47-D SP cells; the statistical results of graph quantification were calculated by the t-test, ${ }^{*} \mathrm{P}<0.05,{ }^{* *} \mathrm{P}<0.01$.

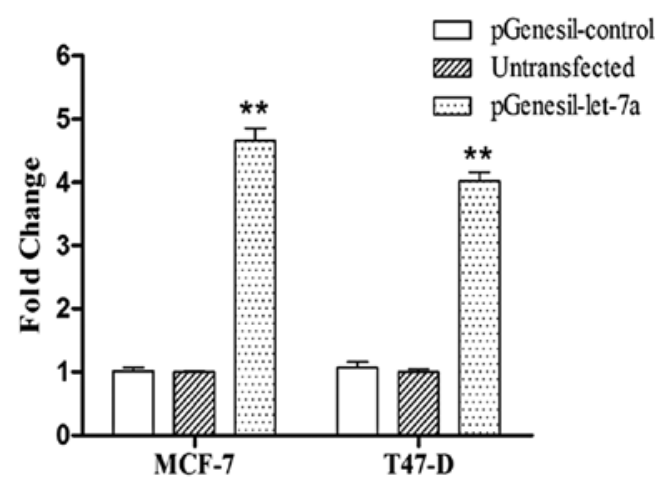

Figure 5. Quantification of the forced overexpression of let-7a. Quantification of expression of let-7a in MCF-7 and T47-D SP cells, compared with control group and negative group. The relative quantities were calculated by the $2^{-\Delta \Delta \mathrm{C} t}$ method using U6 as the internal reference. Statistical analysis was performed using the t-test, ${ }^{* *} \mathrm{P}<0.01$.

\section{Discussion}

CSCs possess lots of fundamental characteristics which are similar to normal stem cells $(31,32)$, and have an enhanced capacity for tumor generation and metastasis, eventually leading to resistance to chemotherapy and tumor recurrence (14). To investigate CSCs, separation is the first and the most crucial procedure. The separation of CSCs from tumor tissues or cell lines is usually based on SP cells, CD $44^{+} / \mathrm{CD} 24^{- \text {/low }}$ and $\mathrm{ALDH}^{+}$phenotypes $(28,29,33-35)$. The use of SP cells is widely accepted, and these cells are identified as an enriched group of CSCs. Based on several experimental and clinical analyses of CSCs in breast tumors, a correlation between the propor-
A

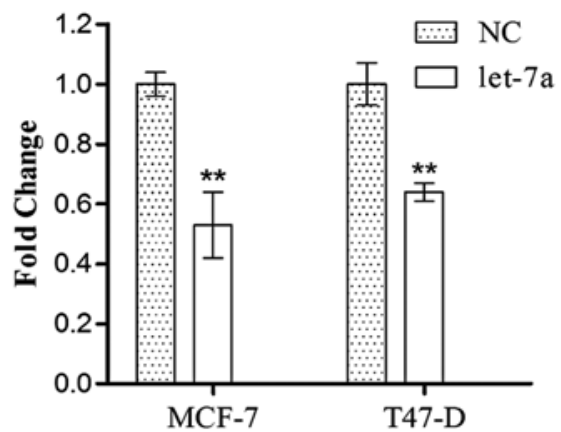

B

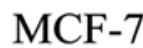

T47-D

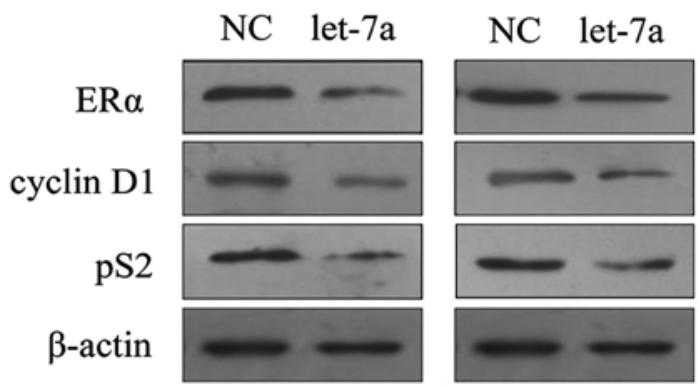

C

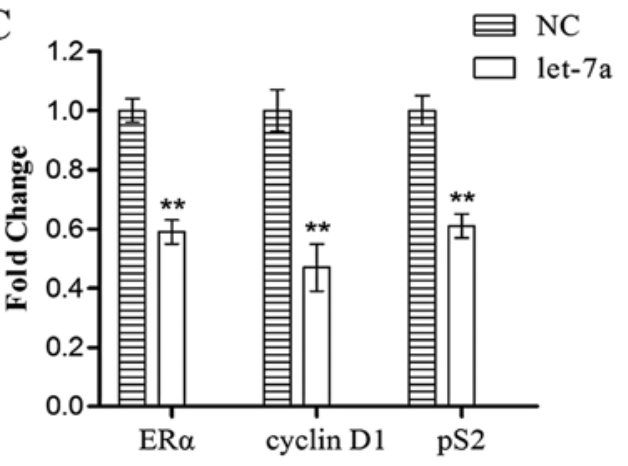

D

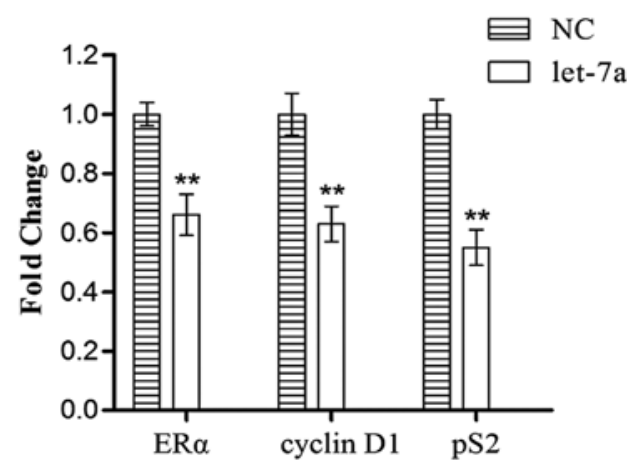

Figure 6. Effect of let-7a on the estrogen receptor (ER) $\alpha$ signaling pathway. (A) Change in ER $\alpha$ mRNA expression after transfection. (B) Effect of let-7a on protein expression of ER $\alpha$, cyclin D1 and pS2 in side population (SP) cells from the MCF-7 and T47-D cell lines after two days. Gray values of expression of ER $\alpha$, cyclin D1 and pS2 in (C) MCF-7 SP cells and (D) T47-D SP cells. Statistical analysis was performed using the $\mathrm{t}$-test, ${ }^{* *} \mathrm{P}<0.01$.

tion of CSCs and poor prognosis has been established (36-39). Therefore, the search for effective therapies and novel strategies which could specifically perish and kill BCSCs is an urgent issue which may aid in the treatment of breast cancer.

The close correlation between breast cancer and ER has been emphasized for decades. The upregulation of ER $\alpha$ is considered an important poor prognostic factor, which can 
A

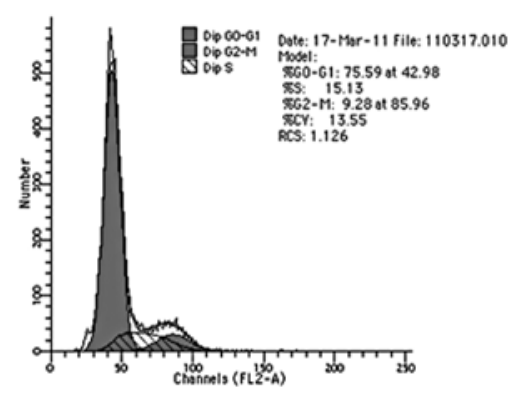

B

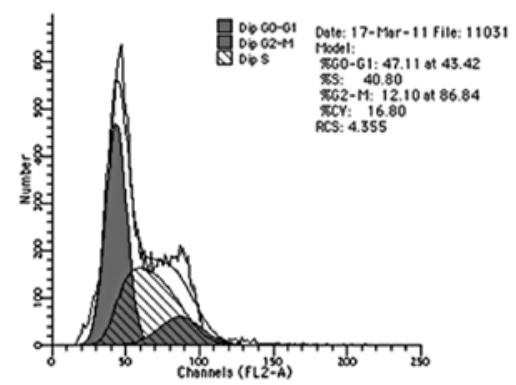

$\mathrm{C}$

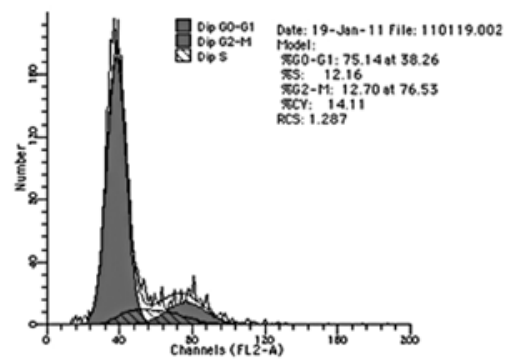

$\mathrm{D}$
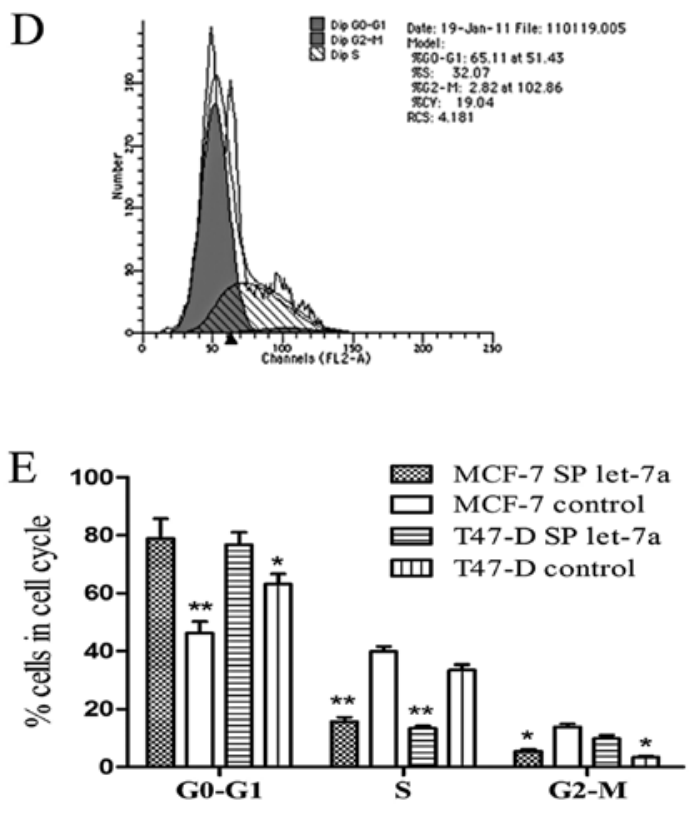

Figure 7. Flow cytometry assessment of the cell cycle. (A) MCF-7 side population (SP) cells were transfected with let-7a; the percentage of SP cells increased in the G0-G1 phase and decreased in the S phase. (B) MCF-7 SP cells transfected with the pGenesil-control plasmid. (C) T47-D SP cells were transfected with let-7a; the percentage of SP cells increased in the G0-G1 phase and decreased in the S phase. (D) T47-D SP cells transfected with pGenesilcontrol plasmid. (E) Bar graph quantification of the cell cycle plots from A-D, ${ }^{*} \mathrm{P}<0.05,{ }^{* *} \mathrm{P}<0.01$.
A

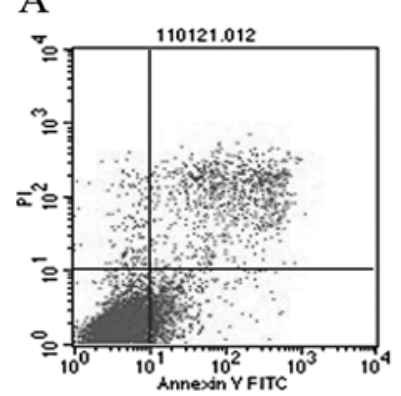

$\mathrm{B}$

$\mathrm{C}$
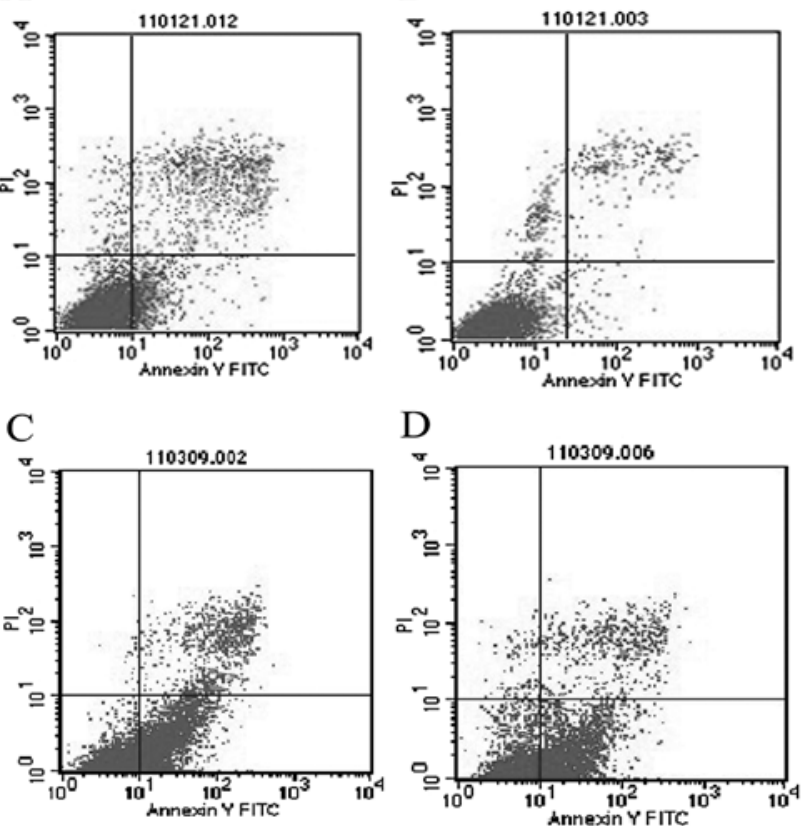

$\mathrm{D}$

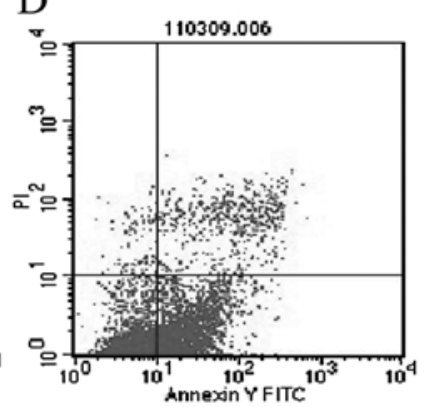

$\mathrm{E}$

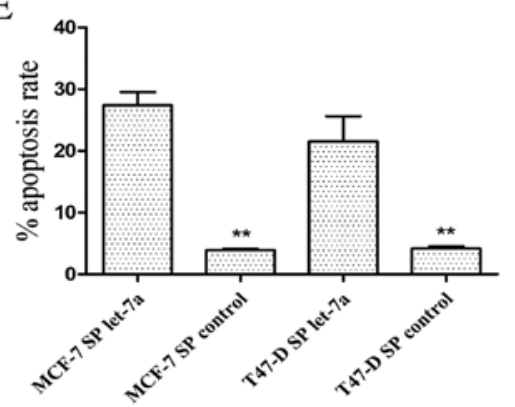

Figure 8. Flow cytometry assessment of the apoptotic rates. (A) The apoptotic rate of MCF-7 side population (SP) cells transfected with let-7a. (B) Control group of MCF-7 SP cells. (C) The apoptotic rate of T47-D SP cells transfected with let-7a. (D) Control group of T47-D SP cells. (E) Bar graph quantification of the apoptotic rates from $\mathrm{A}-\mathrm{D},{ }^{* *} \mathrm{P}<0.01$.

induce aggressive tumorigenesis through the activation of $\mathrm{NF}-\mathrm{\kappa B}, \mathrm{MAPK}$ and other signaling pathways in breast cancer cells. However, the exact function of the ER $\alpha$ signaling pathway in BCSCs has not yet been elucidated. Till now, little information is available regarding ER $\alpha$ in BCSCs (30). It has been confirmed that let-7 can silence multiple oncogenes, such as c-Myc, RAS, HMGA2 and newly discovered ER $\alpha$. The possible interference of let-7 in the ER $\alpha$ transcription and translation process has been reported in a variety of human malignancies $(18,40,41)$; however, the biological effects of let-7 on ER $\alpha$ have not been elucidated in BCSCs. ER $\alpha$ can be directly regulated by let-7 as there is an evident binding site $(18,41)$. Therefore, ER $\alpha$ may be triggered by the downregulation of let-7 miRNAs in BCSCs.

In this study, we demonstrate the possible interactions between let-7 and the ER $\alpha$ signaling pathway; let-7 targets and degrades ER $\alpha$, both in breast tumor tissues and BCSCs. We began with the detection of clinical samples, and observed an inverse correlation between let-7 miRNAs and ER $\alpha$. We then detected the expression levels of ER $\alpha$ downstream genes in SP cells, including cyclin D1 and pS2 to verify our hypothesis. 
The significant correlation between let-7a and $E R \alpha$ status in SP cells suggests that let- 7 is an important regulator of ER $\alpha$ expression and can influence estrogen-dependent CSC proliferation. Finally, we transfected let-7a into SP cells to examine changes in the ER $\alpha$ signaling pathway. The results provide further evidence to support our hypotheses that let-7 regulates the cell cycle and apoptosis of ER-positive BCSCs by influencing $E R \alpha$ and the $E R \alpha$ signaling pathway.

Taken together, our findings indicate that the low expression of let-7 in BCSCs results in estrogen signaling pathway activation, which has a significant effect on estrogen-dependent cells. The low expression of let-7 in MCF-7 and T47-D SP cells did not allow let-7 the opportunity to suppress ER $\alpha$; therefore, ER $\alpha$ was upregulated, accompanied by the high expression of direct downstream genes, such as cyclin D1 and pS2, which play important roles in maintaining the function and character of BCSCs in ER-positive breast cancer. These data shed light onto novel and critical mechanisms by which BCSCs divide and repopulate themselves. As CSCs play a crucial role in cancer recurrence and metastasis, our results may lead to the development of novel strategies for the treatment of patients with ER-positive breast cancer; let-7 miRNAs may be potential agents for anticancer therapy.

\section{Acknowledgements}

This study was supported by the Natural Science Foundation of China, approved ID: 81272418. The authors acknowledge the assistants at the Department of Oncology and the staff of the Key Laboratory of Environment and Genes Related to Disease, Ministry of Education, Faculty of Public Health, College of Medicine, Xi'an Jiaotong University for their technical assistance.

\section{References}

1. Kinch LN and Grishin NV: The human Ago2 MC region does not contain an eIF4E-like mRNA cap binding motif. Biol Direct 4: 2 , 2009.

2. Friedman RC, Farh KK, Burge CB and Bartel DP: Most mammalian mRNAs are conserved targets of microRNAs. Genome Res 19: 92-105, 2009.

3. Wang Z, Li Y, Ahmad A, et al: Targeting miRNAs involved in cancer stem cell and EMT regulation: An emerging concept in overcoming drug resistance. Drug Resist Updat 13: 109-118, 2010.

4. Zimmerman AL and Wu S: MicroRNAs, cancer and cancer stem cells. Cancer Lett 300: 10-19, 2011.

5. Medina PP and Slack FJ: microRNAs and cancer: an overview. Cell Cycle 7: 2485-2492, 2008.

6. Büssing I, Slack FJ and Grosshans H: let-7 microRNAs in development, stem cells and cancer. Trends Mol Med 14: 400-409, 2008.

7. Roush S and Slack FJ: The let-7 family of microRNAs. Trends Cell Biol 18: 505-516, 2008.

8. Johnson CD, Esquela-Kerscher A, Stefani G, et al: The let-7 microRNA represses cell proliferation pathways in human cells. Cancer Res 67: 7713-7722, 2007.

9. Lee YS and Dutta A: The tumor suppressor microRNA let-7 represses the HMGA2 oncogene. Genes Dev 21: 1025-1030, 2007.

10. Muller DW and Bosserhoff AK: Integrin beta 3 expression is regulated by let-7a miRNA in malignant melanoma. Oncogene 27 : 6698-6706, 2008.

11. He XY, Chen JX, Ou-Yang X, Zhang $Z$ and Peng HM: Construction of let-7a expression plasmid and its inhibitory effect on k-Ras protein in A549 lung cancer cells. Nan Fang Yi Ke Da Xue Xue Bao 30: 2427-2431, 2010 (In Chinese).
12. Sureban SM, May R, Ramalingam S, et al: Selective blockade of DCAMKL-1 results in tumor growth arrest by a Let-7a MicroRNA dependent mechanism. Gastroenterology 137: 649-659, 2009.

13. Oliveras-Ferraros C, Cufi S, Vazquez-Martin A, et al: Micro(mi) RNA expression profile of breast cancer epithelial cells treated with the anti-diabetic drug metformin: induction of the tumor suppressor miRNA let-7a and suppression of the TGF $\beta$-induced oncomiR miRNA-181a. Cell Cycle 10: 1144-1151, 2011.

14. Clevers H: The cancer stem cell: premises, promises and challenges. Nat Med 17: 313-319, 2011.

15. Jordan CT, Guzman ML and Noble M: Cancer stem cells. N Engl J Med 355: 1253-1261, 2006.

16. Ito K, Bernardi R, Morotti A, et al: PML targeting eradicates quiescent leukaemia-initiating cells. Nature 453: 1072-1078, 2008.

17. Shachaf CM, Kopelman AM, Arvanitis C, et al: MYC inactivation uncovers pluripotent differentiation and tumour dormancy in hepatocellular cancer. Nature 431: 1112-1117, 2004.

18. Zhao Y, Deng C, Wang J, et al: Let-7 family miRNAs regulate estrogen receptor alpha signaling in estrogen receptor positive breast cancer. Breast Cancer Res Treat 127: 69-80, 2011.

19. Charafe-Jauffret E, Ginestier C, Iovino F, et al: Breast cancer cell lines contain functional cancer stem cells with metastatic capacity and a distinct molecular signature. Cancer Res 69: 1302-1313, 2009

20. Iliopoulos D, Hirsch HA, Wang G and Struhl K: Inducible formation of breast cancer stem cells and their dynamic equilibrium with non-stem cancer cells via IL6 secretion. Proc Natl Acad Sci USA 108: 1397-1402, 2011

21. Goodell MA, Brose K, Paradis G, Conner AS and Mulligan RC: Isolation and functional properties of murine hematopoietic stem cells that are replicating in vivo. J Exp Med 183: 1797-1806, 1996.

22. Challen GA and Little MH: A Side order of dtem vells: the SP phenotype. Stem Cells 24: 3-12, 2006.

23. Ho MM, Ng AV, Lam S and Hung JY: Side population in human lung cancer cell lines and tumors is enriched with stem-like cancer cells. Cancer Res 67: 4827-4833, 2007.

24. Hadnagy A, Gaboury L, Beaulieu R and Balicki D: SP analysis may be used to identify cancer stem cell populations. Exp Cell Res 312: 3701-3710, 2006.

25. Hirsch HA, Iliopoulos D, Tsichlis PN and Struhl K: Metformin selectively targets cancer stem cells, and acts together with chemotherapy to block tumor growth and prolong remission. Cancer Res 69: 7507-7511, 2009.

26. Geng S, Wang Q, Wang J, et al: Isolation and identification of a distinct side population cancer cells in the human epidermal squamous cancer cell line A431. Arch Dermatol Res 303: 181-189, 2011.

27. $\mathrm{Lu} \mathrm{X}, \mathrm{Xu} \mathrm{K}, \mathrm{Lu} \mathrm{H}$, et al: CD44(+)/CD24(-) cells are transit progenitors and do not determine the molecular subtypes and clinical parameters in breast carcinomas. Ultrastruct Pathol 35: 72-78, 2011.

28. Wang J, Guo L-P, Chen L-Z, Zeng Y-X and Lu SH: Identification of cancer stem cell-like side population cells in human nasopharyngeal carcinoma cell line. Cancer Res 67: 3716-3724, 2007.

29. Nakanishi T, Chumsri S, Khakpour N, et al: Side-population cells in luminal-type breast cancer have tumour-initiating cell properties, and are regulated by HER 2 expression and signalling. Br J Cancer 102: 815-826, 2010.

30. Shi GM, Xu Y, Fan J, et al: Identification of side population cells in human hepatocellular carcinoma cell lines with stepwise metastatic potentials. J Cancer Res Clin Oncol 134: 1155-1163, 2008.

31. Dick JE: Stem cell concepts renew cancer research. Blood 112: 4793-4807, 2008.

32. Bhattacharyya S and Khanduja KL: New hope in the horizon: cancer stems cells. Acta Biochim Biophys Sin 42: 237-242, 2010.

33. Idowu MO, Kmieciak M, Dumur C, et al: CD44(+)/CD24(-/low) cancer stem/progenitor cells are more abundant in triple-negative invasive breast carcinoma phenotype and are associated with poor outcome. Hum Pathol 43: 364-373, 2012.

34. Abraham BK, Fritz P, McClellan M, Hauptvogel P, Athelogou $\mathrm{M}$ and Brauch $\mathrm{H}$ : Prevalence of CD $44^{+} / \mathrm{CD} 24^{-/ \text {low }}$ cells in breast cancer may not be associated with clinical outcome but may favor distant metastasis. Clin Cancer Res 11: 1154-1159, 2005 . 
35. Charafe-Jauffret E, Ginestier C, Iovino F, et al: Aldehyde dehydrogenase 1-positive cancer stem cells mediate metastasis and poor clinical outcome in inflammatory breast cancer. Clin Cancer Res 16: 45-55, 2010.

36. Jiao X, Katiyar S, Willmarth NE, et al: c-Jun induces mammary epithelial cellular invasion and breast cancer stem cell expansion. J Biol Chem 285: 8218-8226, 2010.

37. Chuthapisith S, Eremin J, El-Sheemey M and Eremin O: Breast cancer chemoresistance: Emerging importance of cancer stem cells. Surg Oncol 19: 27-32, 2010.

38. Silva IA, Bai S, McLean K, et al: Aldehyde dehydrogenase in combination with CD133 defines angiogenic ovarian cancer stem cells that portend poor patient survival. Cancer Res 71: 3991-4001, 2011.
39. Iinuma $\mathrm{H}$, Watanabe $\mathrm{T}$, Mimori $\mathrm{K}$, et al: Clinical significance of circulating tumor cells, including cancer stem-like cells, in peripheral blood for recurrence and prognosis in patients with Dukes' stage B and C colorectal cancer. J Clin Oncol 29: 1547-1555, 2011.

40. Giovannetti E, Erozenci A, Smit J, Danesi R and Peters GJ: Molecular mechanisms underlying the role of microRNAs (miRNAs) in anticancer drug resistance and implications for clinical practice. Crit Rev Oncol Hematol 81: 103-122, 2012.

41. Sayed D and Abdellatif M: MicroRNAs in development and disease. Physiol Rev 91: 827-887, 2011. 